\title{
THE LAND SECTOR IN THE 2030 EU CLIMATE CHANGE POLICY FRAMEWORK: A LOOK AT THE FUTURE
}

Annalisa Savaresi* and Lucia Perugini**

\begin{abstract}
Under the recently adopted 2030 EU climate change policy framework, land use, land use change and forestry (LULUCF) will for the first time contribute to the EU's economy wide emission reduction target. This article looks at the history of the LULUCF Regulation, analysing its contents in light of the history of international and regional efforts to regulate emissions and removals in this specific sector. It highlights the challenges associated with regulating this specific sector and reviews the regulation, assessing how well it has addressed these challenges.
\end{abstract}

KEYWORDS: climate change, land uses, forestry, LULUCF Regulation.

* Lecturer in Environmental Law, University of Stirling, annalisa.savaresi@stir.ac.uk

** Senior Researcher, Euro-Mediterranean Center on Climate Change (CMCC)

lucia.perugini@cmcc.it 
Forthcoming: Journal for European Environmental \& Planning Law:

\section{Introduction}

Under the 2030 EU climate change policy framework, land use, land use change and forestry (LULUCF) will for the first time contribute to the EU's economy wide emission reduction target, to reduce emissions by $40 \%$ by 2030, when compared with 1990 levels. Forests and agricultural lands cover three quarters of the EU territory and between 1990 and 2016, arable land has decreased, while forestland has increased. Largely thanks to this forest increase, the LULUCF sector in the EU removes greenhouse gases from the atmosphere, even though cropland and grasslands presently are a source of emissions. ${ }^{1}$

The so-called LULUCF Regulation ${ }^{2}$ lays down new rules for the accounting of emissions and removals in this sector and for assessing EU Member States' compliance with these. Since the regulation covers a sector that was not included in the 2020 EU climate package targets, its importance is far-reaching. The negotiation of the regulation, however, was divisive and complex. At first, EU Member States could not agree on whether the regulation was indeed necessary. ${ }^{3}$ Once they did, ${ }^{4}$ they could not agree on its contents. These negotiations were very much influenced by the way this sector has been regulated in the past, not only in the EU, but also in international climate law and policy. They exposed rifts between Member States and their interests, which made it difficult to agree on a common approach. Understanding the background against which the regulation was negotiated and adopted is therefore important to appreciate why the regulation is the way it is, and what to expect from its implementation. This article sets out to do just this. It explains why the LULUCF sector has been so difficult to regulate, by looking at its history in international and EU climate law and policy. It then reviews the regulation, providing an analysis of its contents, and making some predictions concerning its implementation and impacts.

\footnotetext{
${ }^{1}$ This figure is based on 2016 data, as reported in: European Environment Agency, 'Annual European Union Greenhouse Gas Inventory 1990-2016 and Inventory Report 2018' (2018) <https:/www.eea.europa.eu/publications/european-uniongreenhouse-gas-inventory-2018> accessed 28 February 2019.

${ }^{2}$ Regulation (EU) 2018/841 of the European Parliament and of the Council of 30 May 2018 on the inclusion of greenhouse gas emissions and removals from land use, land use change and forestry in the 2030 climate and energy framework, and amending Regulation (EU) No 525/2013 and Decision No 529/2013/EU, OJ L 156, 19.6.2018, p. 1-25, [LULUCF Regulation], Article 1.

${ }^{3}$ As noted for example in G-J. Nabuurs and others, 'A New Role for Forests and the Forest Sector in the EU Post-2020 Climate Targets' (European Forest Institute 2015) $5<$ https://www.efi.int/publications-bank/new-role-forests-and-forestsector-eu-post-2020-climate-targets $>$ accessed 19 February 2019.

${ }^{4}$ European Council, Conclusions, 23 and 24 October 2014, EUCO 169/14, para. 2.14
} 
Forthcoming: Journal for European Environmental \& Planning Law:

\section{The History of LULUCF}

States have long known that land uses and their changes can act as sources of greenhouse gas emissions - releasing carbon in the atmosphere, as a result of deforestation, fires and soil disturbances - or conversely, as sinks - by storing the atmospheric carbon in biomass, in soils, and in harvested wood products. The Intergovernmental Panel on Climate Change (IPCC) prepared a special report on the issue in $2000,^{5}$ and work is currently underway on a new report on desertification, land degradation, sustainable land management, food security, and greenhouse gas fluxes in terrestrial ecosystems. ${ }^{6}$ At the global level, the LULUCF sector accounts for about $4 \mathrm{t} \mathrm{CO}_{2}$ emissions per year (average for the period 2000-2009), representing about $10 \%$ of global $\mathrm{CO}_{2}$ emissions, largely produced by deforestation in developing countries. ${ }^{7}$

In spite of its non-insignificant contribution to global emissions, the LULUCF sector has historically been regarded as difficult to regulate. ${ }^{8}$ To begin with, there was uncertainty over how to quantify LULUCF emissions and removals, and how to measure their reductions/increases.

Furthermore, the accounting for forests posed specific methodological challenges concerning additionality - that is, showing that mitigation efforts have gone beyond business-as-usual and nonanthropogenic effects - and leakage - that is, displacement of emissions to other areas. As forests are characterized by long-term growth dynamics, and by fluctuations linked to their age class structure - so-called age-class legacy effect - accounting for the long term effects of past management decisions is also problematic. ${ }^{9}$

For these reasons, developing rules and methodologies for LULUCF activities has been a long and complex process. While in fact these challenges are not unique to this sector, concerns over the full inclusion of LULUCF emissions in states' carbon budgets were mainly linked to the intrinsic

\footnotetext{
${ }^{5}$ Intergovernmental Panel on Climate Change, Land Use, Land-Use Change, and Forestry a Special Report of the IPCC (Cambridge University Press 2000).

${ }^{6}$ The report is expected to be published in August 2019.

7 Intergovernmental Panel on Climate Change, Climate Change 2013: The Physical Science Basis. Contribution of Working Group I to the Fifth Assessment Report of the Intergovernmental Panel on Climate Change, Cambridge University, Press 2013, Chapter 6, 465-522; Intergovernmental Panel on Climate Change, Climate Change 2014: Mitigation of Climate Change. Contribution of Working Group III to the Fifth Assessment Report of the Intergovernmental Panel on Climate Change, Cambridge University Press 2014, Chapter 11, 811-886; and G. Grassi and others, 'Reconciling Global-Model Estimates and Country Reporting of Anthropogenic Forest CO2 Sinks' (2018) 8 Nature Climate Change 914.

${ }^{8}$ See e.g. K. Dooley and A. Gupta, 'Governing by Expertise: The Contested Politics of (Accounting for) Land-Based Mitigation in a New Climate Agreement' (2017) 17 International Environmental Agreements: Politics, Law and Economics 483; J.H.A. Krug, 'Accounting of GHG Emissions and Removals from Forest Management: A Long Road from Kyoto to Paris' (2018) 13 Carbon Balance and Management 1.

${ }^{9}$ G. Grassi and others, 'The Key Role of Forests in Meeting Climate Targets Requires Science for Credible Mitigation' (2017) 7 Nature Climate Change 220.
} 
difficulties to discern what of the emitted or removed carbon can be attributable to human activities or to natural processes. There was, in other words, some concern that LULUCF carbon 'credits' related to natural processes could undermine the integrity of a country's overall accounting of it emissions and removals. The rules for the accounting of carbon debits and credits in the LULUCF sector have been painstakingly negotiated, with lengthy technical debates over how to address the sector-specific challenges. ${ }^{10}$ This section gives an account of this debate and of the policy solutions devised to tackle these challenges in international and EU climate law and policy, thus providing the backdrop against which the LULUCF Regulation was adopted.

\subsection{LULUCF activities in international climate law and policy}

The 1992 United Nations Framework Convention on Climate Change (UNFCCC) asks its Parties to 'control, reduce or prevent' anthropogenic emissions, including those from agriculture and forestry; to promote the sustainable management, conservation and enhancement of all sinks and reservoirs; and to periodically update and publish inventories reporting national emissions and removals, including from land uses. ${ }^{11}$ However, because of the differentiation between developed and developing countries' obligations under the UNFCCC and the1997 Kyoto Protocol, ${ }^{12}$ these groups of countries have historically been subjected to diversified accounting and reporting obligations, including in the LULUCF sector.

Up until 2020, developed countries may use greenhouse gases emissions and removals from the LULUCF sector to meet their emissions reduction targets for 2020, but only to a limited extent. The complex set of rules on the accounting of LULUCF activities under the Kyoto Protocol has evolved over time. Initially accounting was mandatory only for some activities -namely, afforestation, reforestation, deforestation ${ }^{13}$-but not others - like forest management, cropland management,

\footnotetext{
${ }^{10}$ See e.g. B. Schlamadinger and others, 'A Synopsis of Land Use, Land-Use Change and Forestry (LULUCF) under the Kyoto Protocol and Marrakech Accords' (2007) 10 Environmental Science \& Policy 271; J.G. Canadell and others, 'Factoring out Natural and Indirect Human Effects on Terrestrial Carbon Sources and Sinks' (2007) 10 Environmental Science \& Policy 370; G-J. Nabuurs and others, 'By 2050 the Mitigation Effects of EU Forests Could Nearly Double through Climate Smart Forestry' (2017) 8 Forests 484; G-J. Nabuurs, E.J.M.M. Arets and M-J. Schelhaas, 'Understanding the Implications of the EU-LULUCF Regulation for the Wood Supply from EU Forests to the EU' (2018) 13 Carbon Balance and Management 18; G. Grassi and others, 'Science-Based Approach for Credible Accounting of Mitigation in Managed Forests' (2018) 13 Carbon Balance and Management 8.

${ }^{11}$ UN Framework Convention on Climate Change (Rio de Janeiro, 9 May 1992, in force 21 March 1994) 1771 UNTS 107 [UNFCCC], Article 4.

${ }^{12}$ Kyoto Protocol to the United Nations Framework Convention on Climate Change (Kyoto, 11 December 1997, in force 16 February 2005) 2303 UNTS 14 [Kyoto Protocol], Annex B.

${ }_{13}$ Kyoto Protocol, Article 3.3 and Decision 16/CMP.1, Land use, land-use change and forestry. UN Doc. FCCC/KP/CMP/2005/8/Add.3 (2005).
} 
grazing land management, re-vegetation and wetland drainage and rewetting. ${ }^{14}$ Over time, updated methods to discount emissions due to disturbances, and account for harvested wood products were introduced, as well as the obligation to account for forest management. ${ }^{15}$

Starting with 2013, developed countries have had to follow a 'reference level' approach to the accounting of forest management, whereby net emissions or reductions are assessed against a business-as-usual benchmark - so-called reference level. As a result, if forest management during the commitment period leads to a decrease in the sink, when compared with the reference level, this would result in 'debits'; conversely, if the sink increases more than the reference level, then the difference will result in 'credits'. This reform was introduced in an attempt to fully account for additional mitigation action beyond common practices. The criteria for setting reference levels under the Kyoto Protocol, ${ }^{16}$ however, were not sufficiently detailed, leaving wide margins to accommodate Parties' different interpretations of the reference level. The ambiguity of the criteria put at risk the credibility of the system, allowing Parties to set their reference level in a way that may generate credits in the accounting process, which do not necessarily reflect a real change or improvement in management activities. ${ }^{17}$ In order to address this concern, a 'cap' on credits was introduced to limit the excess of credits from this sector. The cap is equal to $3.5 \%$ of the base year emissions, mostly referring to 1990 levels. ${ }^{18}$

Conversely, developing countries are not subject to any accounting obligations, as they do not have emission reduction targets ${ }^{19}$, but may seek financial support for LULUCF activities, either through the Clean Development Mechanism (CDM) - limited to afforestation and reforestation activities; or REDD + - which covers avoided deforestation and forest degradation, sustainable forest management, as well as afforestation and reforestation. ${ }^{20}$

\footnotetext{
${ }_{15}^{14}$ Decision 2/CMP.7, Land use, land-use change and forestry, UN Doc. FCCC/KP/CMP/2011/10/Add.1 (2011)

15 Decision 2/CMP.6, The Cancun Agreements: Land use, land-use change and forestry, UN Doc. FCCC/KP/CMP/2011/10/Add.1 (2011) and Decision 2/CMP.7, supra note 14.

${ }^{16}$ Decision 2/CMP.7, supra note 14.

17 As argued in G. Grassi and others, 'Science-Based Approach for Credible Accounting of Mitigation In Managed Forests. Carbon Balance and Management' (2018) 13(1), 8.

${ }^{18}$ Decision 2/CMP7, (supra note 14.).

${ }^{19}$ Decision 2/CP.17, Outcome of the work of the Ad Hoc Working Group on Long-term Cooperative Action under the Convention, UN Doc. FCCC/CP/2011/9/Add.1, Annex III (2011)

${ }^{20}$ Decision 1/CP.16 The Cancun Agreements. Outcome of the work of the Ad Hoc Working Group on long-term Cooperative Action under the Convention. UN Doc. FCCC/CP/7/Add.1 (2010)
} 
This fragmented approach has been criticized for not providing adequate incentives for land based mitigation in all countries. ${ }^{21}$ This approach has also engendered perverse outcomes, with bioenergy policies in the US and in the EU leading to no net mitigation, and negative environmental and social impacts in developing countries. ${ }^{22}$

In the lead up to the adoption of the 2015 Paris Agreement, ${ }^{23}$ many advocated for better and less fragmented rules on LULUCF. ${ }^{24}$ The Agreement goes beyond a binary approach to Parties' obligations, asking all Parties to pursue domestic mitigation measures and that a balance between anthropogenic greenhouse gas emissions by sources and removals by sinks be achieved in the second half of this century. ${ }^{25}$ Furthermore, all Parties are encouraged to take action to conserve and enhance, as appropriate, sinks and reservoirs of greenhouse gases, including forests. ${ }^{26}$ As a result, the LULUCF sector plays a pivotal role in the achievement of the Agreement's long-term goal. This evolution is reflected in Parties' Nationally Determined Contributions (NDC), whereby the land sector is expected to contribute to about a quarter of the pledged emission reductions globally. ${ }^{27}$

The Agreement has also levelled Parties obligations in relation to reporting, with some flexibility for developing countries in terms of scope, frequency and level of reporting detail. When accounting for the impact of their mitigation actions, therefore, all Parties 'shall promote environmental integrity, transparency, accuracy, completeness, comparability and consistency, and ensure the avoidance of double counting, ${ }^{28}$ However, a great deal of uncertainty surrounds the methodologies and procedures that Parties will deploy in order to report and account their LULUCF activities, in the context of the new architecture designed by the Paris Agreement.

${ }^{21}$ D. Ellison and others, 'The Incentive Gap: LULUCF and the Kyoto Mechanism before and after Durban' (2013) 5 GCB Bioenergy 599; Nabuurs and others (n 3); C. Parker and others, 'The Land-Use Sector within the Post-2020 Climate Regime' (Nordic Council of Ministers 2014); 'Letter from Scientists to the EU Parliament Regarding Forest Biomass' (https://empowerplants.com, 2018) <https://empowerplants.files.wordpress.com/2018/01/scientist-letter-on-eu-forestbiomass-796-signatories-as-of-january-16-2018.pdf $>$.

${ }^{22}$ See for example A. Gurgel, J.M. Reilly and S. Paltsev, 'Potential Land Use Implications of a Global Biofuels Industry' (2007) 5 Journal of Agricultural \& Food Industrial Organization 1202; E. Gallagher, 'Review of the Indirect Effects of Biofuels Production' (UK Renewable Fuels Agency 2008); T.D. Searchinger and others, 'Europe's Renewable Energy Directive Poised to Harm Global Forests' (2018) 9 Nature Communications 3741; 'Letter from Scientists to the EU Parliament Regarding Forest Biomass'supra note 21.

${ }^{23}$ Paris Agreement (adopted 12 December 2015, entered into force 4 November 2016) 55 ILM 740 [Paris Agreement].

${ }^{24}$ See e.g. Ellison and others, supra note 21; Parker and others, supra note 21; Nabuurs and others, supra note 3.

${ }^{25}$ Paris Agreement, Article 4.1 and 4.2.

${ }^{26}$ Id., Article 5.

${ }^{27}$ Grassi and others, 'The Key Role of Forests in Meeting Climate Targets Requires Science for Credible Mitigation' supra note 9.

${ }^{28}$ Id., Article 4.13. 
The Katowice Climate Package adopted in December 2018 provides general guidance for tracking Parties' progress toward the achievement of the temperature goal enshrined in the Paris Agreement, ${ }^{29}$ and for accounting and tracking progress on the achievement of Parties' NDCs. ${ }^{30}$ While the guidance on accounting in the Katowice Package is general in nature, the LULUCF sector is especially mentioned. Parties are required to explain how natural disturbances, harvested wood products and age class structure are being addressed in their accounting. ${ }^{31}$ Parties should rely on extant guidance, either under the Kyoto Protocol or the UNFCCC, and explain how they draw upon it. ${ }^{32}$ In general, however, the Katowice Package largely leaves it to Parties to choose the modalities and procedures for accounting their emission reductions to be used in their NDCs. The LULUCF Regulation addresses precisely this issue for the EU. ${ }^{33}$

\subsection{LULUCF activities in EU climate change law and policy}

Until 2020, LULUCF activities in the EU will be accounted for under the Kyoto Protocol, but will not count towards the achievement of the EU's internal climate change mitigation targets. At the international level, if the sector results in net debits, the EU will need to use emissions reductions from other sectors to achieve its targets. At the internal EU level, however, LULUCF activities do not count towards the achievement to the EU internal climate change mitigation targets, ${ }^{34}$ neither under the EU Emission Trading System (ETS), ${ }^{35}$ nor under the Effort Sharing Decision (ESD). ${ }^{36}$

The ETS covers approximately $45 \%$ of the EU's emissions, which are produced largely by power generation and manufacturing industries across Member States. ${ }^{37}$ Emissions from other sectors, instead, are addressed in the ESD. While emissions falling in the scope of the EU ETS are regulated

\footnotetext{
${ }^{29}$ Paris Agreement, Article 2.1.a.

${ }^{30}$ Decision 4/CMA.1 Further guidance in relation to the mitigation section of decision 1/CP.21 (2018) UN Doc. FCCC/CP/2018/L.22.

${ }^{31}$ Id., Annex II, para 1.e.

${ }^{32}$ Id.

${ }^{33}$ LULUCF Regulation, recital para. 3.

${ }^{34}$ Decision No 529/2013/EU of the European Parliament and of the Council of 21 May 2013 on accounting rules on greenhouse gas emissions and removals resulting from activities relating to land use, land-use change and forestry and on information concerning actions relating to those activities, OJ L 165, 18.6.2013, p. 80-97.

${ }^{35}$ Decision No 2002/358/EC of the European Council of 25 April 2002 concerning the approval, on behalf of the European Community, of the Kyoto Protocol to the United Nations Framework Convention on Climate Change and the joint fulfilment of commitments thereunder, OJ L 130, 15.5.2002, p. 1-3

${ }^{36}$ Decision No 406/2009/EC of the European Parliament and of the Council of 23 April 2009 on the effort of Member States to reduce their greenhouse gas emissions to meet the Community's greenhouse gas emission reduction commitments up to 2020, OJ L 140, 5.6.2009, p. 136-148

${ }^{37}$ See: $<$ https://ec.europa.eu/clima/sites/clima/files/factsheet_ets_en.pdf $>$ accessed 27 March 2019.
} 
at the EU level, it is the responsibility of Member States to define and implement national policies and measures to limit emissions from the sectors covered by the ESD.

The exclusion of LULUCF activities from the EU's economy wide emission reduction target under the 2020 package was motivated by global and EU-specific concerns. ${ }^{38}$ At the global level, the EU was sceptical about using LULUCF sinks to meet developed countries' targets under the Kyoto Protocol. The EU's scepticism was based partly on concerns about the accuracy of reporting on emissions and sinks; partly on the robustness with which changes could be attributed to human activity; and partly on the risk that the inclusion, particularly of 'unearned' mitigation credits from sinks, could significantly weaken incentives for emission reductions in other sectors. ${ }^{39}$

At the EU level, a study prepared by the EU Commission in 2011 shows how it was widely believed that allowing LULUCF removals to contribute to the achievement of the EU targets would have required a redistribution of efforts amongst Member States. ${ }^{40}$ This in turn would have required a change of key EU climate legislation, because of the high inter-annual variations in LULUCF emissions and removals, and difficulties associated with annual compliance following linear trajectories in emissions levels. ${ }^{41}$ The same report underscored how inclusion of the LULUCF sector would have required special allowances for departures from expected emissions levels, due to uncontrollable disturbance events. ${ }^{42}$ A number of provisions of the ESD would therefore need to be reviewed and possible amended. Equally, inclusion of LULUCF in the EU ETS was ruled out as it would have increased risks of non-permanence of emissions reductions and a loss of simplicity, transparency and predictability. ${ }^{43}$ These considerations brought the EU to exclude removals from the forest sector from the scope of eligible activities to meet the EU's emission targets up to 2020. The EU also decided that credits from forest projects in developing countries could not be traded with those generated in the EU ETS. ${ }^{44}$

\footnotetext{
${ }^{38} \mathrm{G}-J$. Nabuurs and others, supra note 3.

39 As reported in Z.E. Bailey, 'Sink That Sank the Hague: A Comment on the Kyoto Protocol' (2002) 16 Temple International \& Comparative Law Journal 103.

${ }^{40}$ P. Kuikman and others, 'Policy Options for Including LULUCF in the Community Reduction Commitment and Policy Instruments for Increasing GHG Mitigation Efforts in the LULUCF and Agriculture Sectors' (European Commission 2011) $27<$ https://ec.europa.eu/clima/sites/clima/files/forests/lulucf/docs/synthesis_report_en.pdf $>$ accessed 27 March 2019.

${ }^{41}$ Kuikman and others, supra note 40.

42 Id. 7.

${ }^{43}$ Id. 27.

${ }^{44}$ Decision No 280/2004/EC of the European Parliament and of the Council of 11 February 2004 concerning a mechanism for monitoring Community greenhouse gas emissions and for implementing the Kyoto Protocol, OJ L 49, 19.2.2004, p. $1-8$
} 
Even though the EU decided not to use LULUCF credits and debits to achieve its 2020 targets, it still had to account for LULUCF emissions. ${ }^{45}$ The EU LULUCF decision has largely followed the accounting approach adopted under the Kyoto Protocol, with the additional requirement that the reference level include only the effects of policies that were in place by 2009 . While this requirement was aimed to ensure that the reference level would not include policies adopted to meet the objectives of the 2020 climate and energy package, it did not prevent Member States to include the future effects of policies adopted before 2009. For instance, estimated increases in wood harvest to meet the demand of bioenergy on the basis of plans adopted before 2009 could be included, potentially resulting in the overestimation of emissions within the reference level. Such future assumptions were impossible to review, thus potentially opening the way to an overestimation of emissions in the reference level, undermining the integrity of the system.

This approach has attracted much criticism. Grassi and colleagues noted how the inclusion of the effect of future policies had contributed, among others, to a gap between observed harvesting and that included in the reference levels, which resulted in the potential generation of credits equivalent to $1.3 \%$ of the EU total emissions, when considering the accounting limitations for forest management - the so-called $3.5 \%$ cap. ${ }^{46}$ This gap could be the result of several factors, including, for example, the decrease of harvesting as a result of the economic crisis. Whatever the cause of the gap, on average the foreseen effects of policies have not materialised, thus leading to an overestimation of harvesting in the EU's reference level.

It is furthermore important to note that in the EU the LULUCF sector is under pressure, due to the use of wood and other solid biofuels to meet the EU's renewable energy targets. However, the EU's approach to bioenergy has been controversial. Generally, bioenergy generation can have positive, neutral or negative effects on biospheric carbon fluxes, depending on the characteristics of the system, soil and climate factors, the vegetation cover and land-use history in the locations where bioenergy is produced. ${ }^{47}$ Wood and other solid biofuels presently are the most important source of

\footnotetext{
${ }^{45}$ Decision 529/2013/EU, supra note Error! Bookmark not defined..

${ }^{46}$ Grassi and others, 'Science-Based Approach for Credible Accounting of Mitigation in Managed Forests' (n 10).

${ }^{47}$ G. Berndes and others, 'Forest Biomass, Carbon Neutrality and Climate Change Mitigation' (European Forest Institute 2016) <https://www.efi.int/publications-bank/forest-biomass-carbon-neutrality-and-climate-change-mitigation> accessed 19 February 2019.
} 
renewable energy in the EU, accounting for $42.0 \%$ of renewable energy production in $2017,{ }^{48}$ with demand projected to increase in the next decade, as a result of the implementation of the recast Renewables Directive. ${ }^{49}$ When burned for energy generation, however, forest biomass emits greenhouse gases. Under the UNFCCC, bioenergy emissions are considered equal to zero in the energy sector, as they are reported and accounted for in the LULUCF sector. ${ }^{50}$ Therefore, by deciding not to include the LULUCF sector amongst those contributing to the achievement of the 2020 target, the 2020 EU climate framework created a gap, ignoring the effects of any unsustainable exploitation of forest biomass. ${ }^{51}$

In sum, the rules concerning the accounting of LULUCF activities under the 2020 EU climate policy package were considered not sufficiently robust to guarantee a rigorous quantification of the mitigation actions in the forestry sector. Besides, emissions from bioenergy production were not properly accounted for. ${ }^{52}$ The 2020 package, therefore, failed to deliver an economy wide approach, which takes into proper account interactions among sectors, including possible spillover and leakage effects. It is in this context that the LULUCF Regulation was negotiated and eventually adopted.

\section{The LULUCF Regulation}

In 2014, the EU decided to include the LULUCF sector in the EU climate change policy framework to be implemented between 2021 and 2030, as a means to achieve its $40 \%$ economy-wide emission reduction target for that period. Accordingly, the EU's NDC specifies that the modalities of inclusion of the LULUCF sector would be established as soon as technical conditions allow, and in any case before $2020 .^{53}$

\footnotetext{
48 EUROSTAT, Renewable energy statistics. < https://ec.europa.eu/eurostat/statisticsexplained/index.php/Renewable_energy_statistics\#Renewable_energy_produced_in_the_EU_increased_by_two_thirds in_2007-2017> accessed 1 March 2019

${ }^{49}$ Directive 2018/2001 of the European Parliament and of the Council on the promotion of the use of energy from renewable sources, [2018] OJ L328/82

50 See 'IPCC - Task Force on National Greenhouse Gas Inventories' (IPCC 2006) < https://www.ipccnggip.iges.or.jp/public/2006gl/> accessed 27 March 2019; and A. Agostini and others, Carbon Accounting of Forest Bioenergy: Conclusions and Recommendations from a Critical Literature Review, European Commission 2014, $<$ http://dx.publications.europa.eu/10.2788/29442> accessed 27 March 2019.

${ }^{51}$ EU Commission Staff Working Document, Impact Assessment on the role of land use, land use change and forestry (LULUCF) in the EU's climate change commitments (SWD(2012) 40 final), 21

52 EASAC, 'Multi-Functionality and Sustainability in the European Union's Forests' (German National Academy of Sciences Leopoldina 2017) < https://easac.eu/publications/details/multi-functionality-and-sustainability-in-the-europeanunions-forests/> accessed 1 March 2019.

${ }^{53}$ Submission by Latvia and the European Commission on behalf of the European Union and its Member States Riga, 6 March 2015, Intended Nationally Determined Contribution of the EU and its Member States, available at: $<$ https://www4.unfccc.int/sites/ndcstaging/PublishedDocuments/European\%20Union\%20First/LV-03-06-

EU\%20INDC.pdf> accessed 1 March 2019.
} 
As mentioned above, the EU had discarded the option of including LULUCF emissions in the EU ETS from the outset. ${ }^{54}$ Inclusion in the ETS would have required that land holdings be subjected to rules concerning monitoring and reporting comparable to those for installations covered by the ETS. The EU Commission considered impractical the option of developing a monitoring system for all types of land, arguing that it would be impossible to guarantee the compatibility/consistency of holding level estimates with those of national data, and to cover projected monitoring and administrative costs of the system. ${ }^{55}$ Consequently, the Commission identified two main options for including emissions and removals from LULUCF in the 2030 climate change mitigation framework: developing a separate LULUCF pillar in EU climate policy; or including LULUCF in the Climate Action Regulation, ${ }^{56}$ which covers the sectors currently included in the ESD for the period 2021-2030 - i.e. agriculture, transport, waste and buildings. ${ }^{57}$

After lengthy debate, a hybrid approach prevailed. The LULUCF Regulation adopted in May 2018 establishes a LULUCF pillar in EU climate policy, with dedicated rules and the commitment that the sector remain neutral in terms of accounted net emissions - the so-called 'no debit rule' ${ }^{58}$ If the LULUCF sector generates debits or credits, these will contribute, to a certain extent, to the emission reduction target under the Climate Action Regulation. ${ }^{59}$ The idea was therefore to use LULUCF removals as a 'flexibility tool' to compensate for the lower mitigation potential in the agriculture sector, where emissions mainly relate to dairy production and fertilization, which are commonly deemed to be more difficult to reduce without repercussions on food production and security. ${ }^{60}$

\footnotetext{
${ }^{54}$ Impact Assessment of the Directive of the European Parliament and of the Council amending Directive 2003/87/EC so as to improve and extend the EU greenhouse gas emission allowance trading system, COM(2008) 16 final, SEC(2008) 53; and Extended Impact Assessment on the Directive of the European Parliament and of the Council amending Directive establishing a scheme for greenhouse gas emission allowance trading within the Community in respect of the Kyoto Protocol's project based mechanisms, COM(2003) 403 final, SEC(2003) 785. See also Kuikman and others (n 40).

${ }_{55}$ Commission Staff Working Document, Impact Assessment on the role of land use, land use change and forestry (LULUCF) in the EU's climate change commitments Accompanying the document Proposal for a Decision of the European Parliament and of the Council on accounting rules and action plans on greenhouse gas emissions and removals resulting from activities related to land use, land use change and forestry, COM(2012) 93 final, SWD(2012) 40 final, para 8.5

${ }^{56}$ Regulation (EU) 2018/842 of the European Parliament and of the Council of 30 May 2018 on binding annual greenhouse gas emission reductions by Member States from 2021 to 2030 contributing to climate action to meet commitments under the Paris Agreement and amending Regulation (EU) No 525/2013, PE/3/2018/REV/2 OJ L 156, 19.6.2018, p. 26-42

${ }^{57}$ Id., section 4.

${ }^{58}$ LULUCF Regulation, Article 4.

${ }^{59}$ Regulation (EU) 2018/842 of the European Parliament and of the Council of 30 May 2018 on binding annual greenhouse gas emission reductions by Member States from 2021 to 2030 contributing to climate action to meet commitments under the Paris Agreement and amending Regulation (EU) No 525/2013, PE/3/2018/REV/2 OJ L 156, 19.6.2018, p. 26-42

${ }^{60}$ EU Council Conclusions, supra note 4.
} 


\subsection{Accounting rules}

The matter of how to set forest reference levels was at the centre of a heated debate that lasted two years. The main difficulty was to overcome the shortcomings of current legislation, ${ }^{61}$ while preserving incentives for the sustainable use of forest resources, also in light of future bioenergy demands. The EU Commission's proposal suggested calculating reference levels on the basis of historical practices, but considering future forest characteristics in terms of age class structure. ${ }^{62}$ Some viewed this proposal as the most robust and verifiable system. ${ }^{63}$ Others, however, feared that it would limit the economic potential of the forestry sector, with possible leakage in terms of wood and biomass outsourcing and increase use of competing high-energy material. ${ }^{64}$

This debate concluded with the decision to base reference levels on the continuation of forest management practices that were in place between 2000-2009. ${ }^{65}$ Member States' projections have to include historical forest management practices in reference levels for the 2021-2030 period, considering forests' future age class structure. ${ }^{66}$ De facto, this method factors out the future impact of age-class legacy of forests, while rewarding countries that implement measures that increase forest sinks vis-à-vis past management practices. ${ }^{67}$ As a result, the forest sector is assimilated to other sectors included in the scope of the Climate Action Regulation, which are all accounted for on the basis of deviations from past conditions, using 2005 as the baseline year. However, the credits generated by the managed forest area are still subject to a cap, equal to $3.5 \%$ of 1990 emissions.

The LULUCF Regulation asks Member States to submit their forest reference levels for the period 2021-2025 by 31 of December $2018 .^{68}$ These reference levels are presently under review by the Commission, in consultation with experts appointed by Member States. The Commission may

\footnotetext{
${ }^{61}$ Decision 529/2013/EC, supra note Error! Bookmark not defined..

${ }^{62}$ European Commission. Proposal for a Regulation of the European Parliament and of the Council on the inclusion of greenhouse gas emissions and removals from land use, land use change and forestry into the 2030 climate and energy framework and amending Regulation No 525/2013 of the European Parliament and the Council on a mechanism for monitoring and reporting greenhouse gas emissions, 11494/16COM (2016).

${ }^{63}$ G. Grassi and others, 'Science-Based Approach for Credible Accounting of Mitigation in Managed Forests' (2018) 13 Carbon Balance and Management 8.

${ }^{64}$ A.M.I. Kallio and others, 'Economic Impacts of Setting Reference Levels for the Forest Carbon Sinks in the EU on the European Forest Sector' (2018) 92 Forest Policy and Economics 193.

${ }^{65}$ Grassi and others, 'Science-Based Approach for Credible Accounting of Mitigation in Managed Forests', supra note 63.

${ }^{66}$ LULUCF Regulation, Article 8.5.

${ }^{67}$ Id., Article 8.3

${ }^{68} \mathrm{Id}$.
} 
decide to issue recommendations for revised reference levels, which will have to be submitted by December 2019. ${ }^{69}$

Member States' accounts must include also emissions and removals from land subject to afforestation or reforestation activities in the past 20 years (or 30 years, if duly justified). Net emissions and removals during the accounting period will be considered as a whole, thus fully account for credits derived by reforestation activities, and on the contrary fully account for debits generated by deforestation. ${ }^{70}$ Furthermore Member States' accounts must include net emissions and removals from cropland and managed grassland areas, using the period 2005-2009 as the baseline. ${ }^{71}$ The use of multiple years, rather than a single base year, has the advantage to discount possible annual variations, lowering the risk of the selection of highly favourable or unfavourable base years, which may benefit some Member States and not others. Wetland management will be included in 2026, with the same accounting method as cropland and grassland. ${ }^{72}$

The LULUCF Regulation allows Member States to exclude from their accounts emissions and subsequent removals caused by natural disturbances on forest land - like fires, storms, large pest outbreaks, etc. - only insofar as they comply with certain criteria. These requirements provide that emissions should be beyond certain thresholds, and that the affected land should be georeferenced, tracked and not converted in other land uses following the disturbances. ${ }^{73}$ Harvested wood products are also accounted for, considering the average time that the carbon remains stored in various products - paper, panel and saw wood. The aim is to acknowledge the positive contribution of wood, especially as a building material, with the twofold advantage of storing carbon, while replacing more emission intensive materials, such as iron and concrete. Finally, the regulation does not subject harvested wood products to a cap. As a result, carbon in the wood products is fully accounted for.

\subsection{Flexibility}

As anticipated, the regulation provides a set of 'flexibility' arrangements. To address the concern of a potential oversupply of carbon credits, the contribution of the LULUCF sector to the achievement of the Climate Action Regulation target is capped to 280 million tons of net removals for the period

\footnotetext{
${ }^{69}$ Id., Article 8.6.

${ }^{70}$ Id., Article 6.

${ }^{71}$ Id., Article 7.

${ }^{72}$ Id.

${ }^{73}$ Id., Article 10.
} 
Forthcoming: Journal for European Environmental \& Planning Law:

2021-2030 - inter-pillar flexibility. ${ }^{74}$ This amount corresponds to $1 \%$ of the annual ESD emissions in 2005. Considering that this amount refers to a 10 -year period, the potential contribution of the LULUCF sector to the achievement of the EU 2030 targets is extremely limited. Within the sector itself, Member States can compensate debits in one land use category with credits from one period to another - intra-account flexibility. It is furthermore possible to transfer credits from one Member State to another, when a surplus of net removals is generated, beyond those that may be transferred to the climate action sectors within the cap - intra-pillar flexibility (see figure 1).

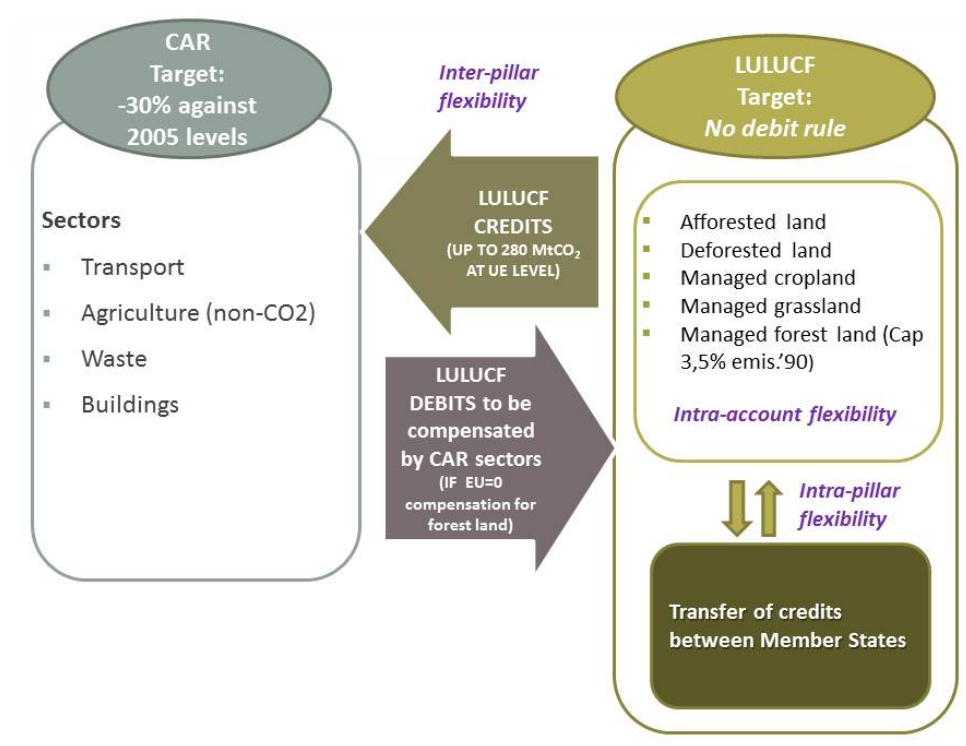

Figure 1- Interaction between the LULUCF and Climate Action pillars and related flexibilities

As a result of these arrangements, if the LULUCF sector produces net emissions, other sectors covered by the Climate Action Regulation will need to achieve additional emission reductions to compensate for LULUCF debits. In this context, however, Member States are allowed some flexibility for managed forests. The regulation in fact provides the possibility to 'compensate' the net debits deriving from managed forests. This compensation can be carried out only provided that at the EU level, emissions accounted for in the LULUCF sector do not exceed total removals overall, and that the Member State affected by the debt demonstrates that it is implementing or has planned measures to increase its forest sinks. These net emissions can be compensated up to a certain level, which varies from one member state to the other - ranging from -61,5 millions of $\mathrm{CO}_{2}$ equivalent, to $-0,03 \mathrm{MCO}_{2}$ eq. ${ }^{75}$ An extra compensation budget of 10 millions of tons of $\mathrm{CO}_{2}$ was

\footnotetext{
${ }_{75}^{74}$ Climate Action Regulation 2018/842, Article 7

${ }^{75}$ LULUCF Regulation, Annex VII.
} 
Forthcoming: Journal for European Environmental \& Planning Law:

granted specifically to Finland, ${ }^{76}$ which has the highest percentage of forest area coverage in the EU $(73 \%)$, with biomass contributing to around $80 \%$ of its renewable energy production. ${ }^{77}$

Largely because of these provisions, the LULUCF Regulation has received a lukewarm reception from civil society, which has described it as a 'missed opportunity'. ${ }^{78}$ The main criticism concerns the possibility to use LULUCF removals to offset emissions in other sectors covered by the Climate Action Regulation. ${ }^{79}$ Indeed, the EU's approach to the LULUCF sector has already been challenged in climate litigation suits, whereby citizens and civil society organisations are contesting the EU's lack of climate ambition before the Court of Justice of the EU, as well as its reliance on biomass to produce renewable energy. ${ }^{80}$

\section{Conclusion}

The troubled history of the LULUCF sector in international and regional climate policy goes a long way to explain why the LULUCF Regulation has received so much attention. It seems beyond doubt that the regulation has significantly advanced accounting rules in a sector that was previously only partially addressed in EU climate law and policy. The regulation has increased transparency and the comprehensiveness of accounting, establishing the conditions to keep better track of mitigation activities in the forest sector, with much improved criteria for setting reference levels. The regulation has also taken the largely overdue step to include the contribution of the LULUCF sector to the achievement of the EU's mitigation target, even if only to a very limited extent. Still, the uneven mitigation potential in EU Member States, and the interlinkages between the LULUCF and the energy sectors have made the negotiations of the LULUCF Regulation exceptionally complex. The outcome of these negotiations is equally complex and difficult to understand. The convoluted rules that limit the use of credits, together with the possibility to compensate net debits from forest management at the level of single member state, fail to fully capture emissions and removals from EU forests, thus rendering accounting in this sector still incomplete. This is a significant shortcoming, as the use of accounting systems that fully reflect changes in the concentration of greenhouse gases in the atmosphere is an obligation under the Paris Agreement, which the EU has at least in part eluded.

\footnotetext{
${ }^{76}$ Id., Article 13.4

${ }_{78}^{77}$ EUROSTAT, supra note 48.

78 FERN, 'The EU's New LULUCF Regulation: Is It Fit for (Climate) Purpose?' (17 April 2018) $<$ https://fern.org/LULUCFRegulationResult> accessed 28 February 2019.

${ }^{79}$ Id.

${ }^{80}$ See: <https://peoplesclimatecase.caneurope.org/> accessed 2 November 2018; and <http://eubiomasscase.org/> accessed 27 March 2019.
} 
Forthcoming: Journal for European Environmental \& Planning Law:

Furthermore, the LULUCF Regulation does very little to incentivise virtuous forest management in the EU. The desire to limit the contribution of this sector to the achievement of the EU's 2030 target is understandable: the $40 \%$ target enshrined in the 2030 package has been criticised by many as inadequate, and has itself become the target of climate change litigation before the CJEU. ${ }^{81}$ Fully including the LULUCF sector towards the achievement of the $40 \%$ target would have de facto lowered the level of EU's ambition. A better course of action would have been to adopt a higher target, and to allow all sectors - including credits from LULUCF activities - to contribute to its achievement.

Instead, the LULUCF Regulation largely relies on EU Member States' willingness to do the right thing, giving them little incentives to do so. Whether they will exercise this freedom wisely, remains to be seen. What seems certain is that the regulation leaves the large potential of the LULUCF sector in the EU to contribute to climate change mitigation untapped.

Admittedly, the balance between the supply of bioenergy and other economic, social and environmental services is hard to strike in this sector, and policy interventions may have multiple consequences, as well as benefits. Like when it trialled the world's first carbon market, with the LULUCF Regulation the EU has pioneered the regulation of a new, difficult area of climate law and policy, moving ahead of other countries. Whether or not the EU has demonstrated actual leadership in this process, however, remains to be seen. At the very least, others will benefit from learning from the EU's travails, including its mistakes.

\footnotetext{
${ }^{81}$ In the context of the so-called People's Climate case, supra note 80.
} 